\title{
Evaluation of Glutathione S-Transferase Inhibition Effects on Idiopathic Pulmonary Fibrosis Therapy with a Near-Infrared Fluorescent Probe in Cell and Mice Models
}

\author{
$\mathrm{Na} \mathrm{He}, \#, \dagger, \|$ Song Bai, ${ }^{\#, \dagger, \|}$ Yan Huang, ${ }^{\ddagger}$ Yanlong Xing, ${ }^{\S}$ Lingxin Chen, ${ }^{*}, \odot$ Fabiao Yu, ${ }^{*, \S \odot ~}$ \\ and Changjun $\mathrm{Lv}^{*}, \dagger, \|$

\begin{abstract}
${ }^{\dagger}$ Department of Respiratory Medicine, Binzhou Medical University Hospital, Binzhou 256603, China
${ }^{\ddagger}$ Key Laboratory of Coastal Environmental Processes and Ecological Remediation, Yantai Institute of Coastal Zone Research, Chinese Academy of Sciences, Yantai 264003, China

${ }^{\S}$ Institute of Functional Materials and Molecular Imaging, College of Clinical Medicine, Key Laboratory of Hainan Trauma and Disaster Rescue, College of Emergency and Trauma, Hainan Medical University, Haikou 571199, China
\end{abstract} \\ "Medicine Research Center, Institute of Molecular Medicine, Binzhou Medical University, Yantai 264003, China
}

Supporting Information

ABSTRACT: Idiopathic pulmonary fibrosis (IPF) is a lung-limited and progressive fibrotic disease. The early diagnosis and therapies of IPF are still full of clinical challenges. Glutathione S-transferase (GSTs) plays significant roles in promoting the formation of pulmonary fibrosis. Herein, we report a fluorescent probe (Cy-GST) for the detection of GSTs concentration fluctuations in cells and in mice models. The probe can selectively and sensitively respond to GSTs with an "off-on" type fluorescence switch. Our results demonstrated that the level of intracellular GSTs increase in the pulmonary fibrosis cells and mice models. And the IPF patients hold high levels of GSTs concentrations. Thus, GSTs are likely to play important roles in pulmonary fibrosis. The inhibitor of GSTs TLK117 can reduce the severity of pulmonary fibrosis. The synergistic treatment of TLK117 and pirfenidone have better therapeutic effects than only using pirfenidone in pulmonary fibrosis mice models. The level of GSTs in IPF may be a new potential marker for IPF diagnosis. And the inhibition of GSTs may be a new therapeutic strategy for IPF treatment.

diopathic pulmonary fibrosis (IPF) is the most common idiopathic interstitial pneumonia, involving a heterogeneous group of chronic progressive disorders. ${ }^{1}$ The IPF patients suffer from a median survival of 2.9 years after diagnosis. However, there is no exact clinical feature to be associated with the development of fibrosing lung disease. Clinically, the treatments of IPF are only to delay disease progression, reduce symptoms, prevent acute exacerbations, and finally prolong survival. Therefore, the high morbidity and mortality have prompted many efforts to develop effective therapeutic methods. Until now, only two therapeutic drugs, pirfenidone (PFD) and nintedanib, have been approved for the special treatment of IPF. ${ }^{2,3}$ PFD is a small-molecule drug with antifibrotic and anti-inflammatory properties, and nintedanib is a tysosine kinase inhibitor which was originally used as an antivascular agent for oncology indications. Compared to other treatment methods for IPF, both drugs showed obvious effects on controlling the disease progression. However, neither PFD nor nintedanib can be used to cure IPF. ${ }^{2,3}$ Therefore, there is an urgent need to establish efficacious therapies for IPF; even the process is undoubtedly full of challenges. ${ }^{4}$
Although the pathogenic mechanism of IPF has not been fully understood yet, the IPF patients are significantly suffering from high levels of oxidative stress. ${ }^{5}$ The recent examinations focus on the antioxidant effects of $N$-acetylcysteine during the progression of IPF. It is suggested that the intracellular redox state may play crucial roles in the progression of IPF. ${ }^{6}$ Glutathione S-transferases (GSTs) contribute to defense of biomacromolecule from oxidative stress by repairing the damage of membrane phospholipid and inhibiting the induction of microsomal peroxidation. ${ }^{7}$ GSTs involve a superfamily of omnipresent and multifunctional enzymes; they all feature their capacity to catalyze the nucleophilic addition of glutathione (GSH) to a wide variety of chemicals with electrophilic functional groups, including products of oxidative stress and chemical carcinogens. As the predominant GSTs isozyme, the Pi isoform GSTP expressed primarily in lung, which is a mediator of S-glutathionylation in lung airway

Received: February 7, 2019

Accepted: March 14, 2019

Published: March 14, 2019 


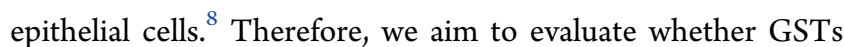
play roles in the treatment of IPF.

Several methods have been developed for the detection of GSTs, such as the analysis of derivatives from 2,4dinitrochlorobenzene (CDNB), ${ }^{9-11} \mathrm{UV}$ spectroscopy, ${ }^{12}$ and bioluminescent analysis. ${ }^{13}$ These assays can be used to detect and track GSTs in cell lysates or in vitro; however, they fail to provide in situ and complete real-time information on these enzymes in living cells and in vivo. Fluorescence bioimaging technology coupled with small-molecule fluorescent probes has been indispensably exploited to visualize biospecies and biological events in living systems because of its advantages in high sensitivity, high spatial and temporal resolution, noninvasive and rapid analysis, and in situ and real-time detection. ${ }^{14-17}$ Small-molecule fluorescent probes are easier to implement in the capture of various biological targets because of their versatile chemical structure modification. ${ }^{18-22}$ This also allows for creating a design strategy of a fluorescence probe for a certain enzyme. To be sure, the small-molecule fluorescent probes have proved to be powerful tools in detecting and imaging enzymes in living systems. ${ }^{23-25}$ The development of small-molecule enzymatic fluorescent probes for GSTs imaging has been elegantly achieved. ${ }^{26-30}$ These presented probes are mainly designed on the basis of the strong nucleophilic properties of GSH in the presence of GSTs, such as Michael addition, halogen nucleophilic substitution, and the cleavage of sulfonamide. However, the emission region of all these GSTs fluorescent probes locate in the visible-light region, which limit their biological applications in vivo because of the photodamage to biosamples and the interference from autofluorescence. ${ }^{31}$ The shallow penetration of the visible region makes the minimally invasive deep tissue imaging in clinical applications impossible. Therefore, it is desirable to acquire a new fluorescent probe whose excitation and emission wavelength locate in the near-infrared (NIR) region. ${ }^{32}$ Moreover, nearly all of the developed GSTs probes focus on the imaging of GSTs on the level of cells, but not animals. Compared to the in situ visual inspection in cells, imaging of GSTs in tissues or animals can directly provide the biodistribution of GSTs in the long-term dynamic processes during disease progression instead of in a short time or in the local range in cells. To address these challenges, we devote efforts to the development of highly sensitive small-molecule NIR fluorescent probe for the detection and imaging of GSTs in living cells and in vivo.

Herein, we conceived a new NIR fluorescent probe Cy-GST for the detection of GSTs in living cells and in vivo. The probe exhibited a specific substrate for the recombinant human GSTP1-1 (hGSTP1) and could provide high sensitivity and selectivity toward GSTs in cells. The results demonstrated that the level of GSTs increased in pulmonary fibrosis cells, IPF mice models, and IPF patients. To the best of our knowledge, Cy-GST is the first fluorescence probe for imaging GSTs and providing direct evidence on the relationship between the level of GSTs and IPF in cells and in vivo. We also confirmed that the synergy of GSTs inhibitor and PFD resulted in a better therapeutic effect than the administration of PFD alone. The inhibition of GSTs implied the potential for synergistic PFD treatment of IPF. In this regard, the as-synthesized probe $\mathrm{Cy}$ GST will be a potential powerful tool for the diagnosis and therapy of IPF in clinics in the future.

\section{EXPERIMENTAL SECTION}

All the details of cell cultures, tissue sections, Western blot analysis, mice imaging, and clinical samples can be found in the Supporting Information.

Synthesis of Compound 2. The synthesis and characterization of compound $\mathbf{1}$ is shown in the Supporting Information. Compound 1 (1.222 g, $2 \mathrm{mmol})$, methylamine hydrochloride $(1.332 \mathrm{~g}, 20 \mathrm{mmol})$, and triethylamine $(2.02 \mathrm{~g}$, $2.8 \mathrm{~mL}, 20 \mathrm{mmol}$ ) were dissolved in $50 \mathrm{~mL}$ of anhydrous dimethyl formamide (DMF). The mixture was stirred for $24 \mathrm{~h}$ at $40{ }^{\circ} \mathrm{C}$ under an $\mathrm{Ar}$ atmosphere. The crude product was purified on silica gel chromatography (200-300 mesh) with gradient eluent of $\mathrm{CH}_{2} \mathrm{Cl}_{2}: \mathrm{CH}_{3} \mathrm{OH}\left(100 \% \mathrm{CH}_{2} \mathrm{Cl}_{2}\right.$ to $90: 10 \mathrm{v} /$ $\mathrm{v})$ to afford compound 2 as a deep blue solid (1.05 g, yield 87\%). ${ }^{1} \mathrm{H} \mathrm{NMR}\left(\mathrm{CDCl}_{3}-d_{1}, 500 \mathrm{MHz}\right) \delta(\mathrm{ppm}): 10.36(\mathrm{~s}$, $1 \mathrm{H}), 8.13-8.12(\mathrm{~d}, J=8.2 \mathrm{~Hz}, 2 \mathrm{H}), 7.86-7.82(\mathrm{~m}, 6 \mathrm{H})$, 7.54-7.52 (m, 2H), 7.35 (s, 2H), 7.17-7.15 (m, 2H), 5.59$5.56(\mathrm{~d}, J=12.6 \mathrm{~Hz}, 2 \mathrm{H}), 3.95-3.93(\mathrm{~m}, 4 \mathrm{H}), 3.78-3.60(\mathrm{~m}$, $4 \mathrm{H}), 2.58-2.56(\mathrm{~m}, 4 \mathrm{H}), 2.02-1.85(\mathrm{~m}, 11 \mathrm{H}), 1.67(\mathrm{~m}, 2 \mathrm{H})$, 1.40-1.27 (m, 6H). ${ }^{13} \mathrm{C}$ NMR $\left(\mathrm{CDCl}_{3}-d_{1}, 125 \mathrm{MHz}\right) \delta$ (ppm): 170.29, 167.37, 154.49, 140.01, 135.96, 131.49, 130.56, 129.74, 129.71, 129.63, 128.75, 127.24, 123.45, 122.15, 119.04, 109.64, 109.19, 92.20, 49.28, 37.67, 37.25, 28.12, 26.18, 21.25, 11.61. LC-MS $\left(\mathrm{ESI}^{+}\right): m / z \mathrm{C}_{43} \mathrm{H}_{48} \mathrm{~N}_{3}{ }^{+}$calcd 606.3843, found $\left[\mathrm{M}^{+}\right] 606.5778$.

Synthesis of Probe Cy-GST. 3,4-Dinitrobenzoic acid $(0.212 \mathrm{~g}, 1 \mathrm{mmol})$ and triphosgene $(0.9 \mathrm{~g}, 3 \mathrm{mmol})$ was dissolved in $100 \mathrm{~mL}$ of anhydrous $\mathrm{CH}_{2} \mathrm{Cl}_{2}$ under $\mathrm{Ar}$ atmosphere. The mixture was suspended at $0{ }^{\circ} \mathrm{C}$, and then 1 $\mathrm{mL}$ of $N, N$-diisopropylethylamine (DIPEA) was added. The reaction lasted for $30 \mathrm{~min}$. After the solvent was removed in vacuum, the obtained residue was dissolved in $50 \mathrm{~mL}$ of anhydrous $\mathrm{CH}_{2} \mathrm{Cl}_{2}$, and DIPEA $(1 \mathrm{~mL})$ and 4-dimethylaminopyridine (DMAP) (20 mg) were added. Compound 1 $(0.121 \mathrm{~g}, 0.2 \mathrm{mmol})$ in $\mathrm{CH}_{2} \mathrm{Cl}_{2}(10 \mathrm{~mL})$ was added to the above solution and then the reaction mixture was stirred at 25 ${ }^{\circ} \mathrm{C}$; thin-layer chromatography (TLC) monitored the reaction until the starting material was completely consumed. The obtained solid residue was purified through a silica gel chromatograph (200-300 mesh) with gradient eluent (from $100 \% \mathrm{CH}_{2} \mathrm{Cl}_{2}$ to $\mathrm{CH}_{2} \mathrm{Cl}_{2}: \mathrm{CH}_{3} \mathrm{OH}, 85: 15$, v/v) to obtain $\mathrm{Cy}$ GST as a green solid (126 mg, yield 79\%). ${ }^{1} \mathrm{H}$ NMR (DMSO$\left.d_{6}, 500 \mathrm{MHz}\right) \delta(\mathrm{ppm}): 8.78(\mathrm{~s}, 1 \mathrm{H}), 8.61-8.48(\mathrm{~m}, 2 \mathrm{H})$, $8.32-8.27(\mathrm{~m}, 2 \mathrm{H}), 8.12-8.11(\mathrm{~d}, J=5.6 \mathrm{~Hz}, 1 \mathrm{H}), 7.78-7.50$ $(\mathrm{m}, 6 \mathrm{H}), 7.41-7.22(\mathrm{~m}, 2 \mathrm{H}), 7.09(\mathrm{t}, J=7.8 \mathrm{~Hz}, 1 \mathrm{H}), 6.42-$ $6.24(\mathrm{~m}, 4 \mathrm{H}), 4.25-4.15(\mathrm{q}, J=7.4 \mathrm{~Hz}, 4 \mathrm{H}), 3.54(\mathrm{~s}, 3 \mathrm{H})$, $2.70-2.66(\mathrm{t}, J=6.4 \mathrm{~Hz}, 4 \mathrm{H}), 1.92(\mathrm{~s}, 6 \mathrm{H}), 1.52-1.33(\mathrm{~m}$, $11 \mathrm{H}), 1.29-1.26(\mathrm{~m}, 3 \mathrm{H}) .{ }^{13} \mathrm{C}$ NMR (DMSO-d $\left.d_{6}, 125 \mathrm{MHz}\right) \delta$ (ppm): 173.00, 169.01, 142.48, 142.11, 141.75, 141.62, 140.70, $140.25,139.77,139.72,138.67,134.29$, 134.24, 131.07, 130.36, $129.41,128.29,127.99,127.26,125.36,122.97,122.40,111.94$, $111.59,110.90,101.06,50.97,49.21,31.74,29.50,28.38$, $27.90,26.95,24.09,12.97,12.57$. LC-MS $\left(\mathrm{ESI}^{+}\right): \mathrm{m} / z$ $\mathrm{C}_{50} \mathrm{H}_{50} \mathrm{~N}_{5} \mathrm{O}_{5}{ }^{+}$calcd. 800.3806, found $\left[\mathrm{M}^{+}\right]$800.1311.

Animal Model. C57BL/6 mice (8 weeks) were obtained from the Model Animal Research Center of Nanjing University (Nanjing, China). All animal experiments were performed in accordance with the regulations established by the Committee on the Ethics of Animal Experiments of Binzhou Medical University. The mice were housed under a 12-h light/dark cycle and were allowed free access to food and water. The bleomycin animal model was administered with $5 \mathrm{mg} / \mathrm{kg}$ 
bleomycin dissolved in saline via single intratracheal instillation under anesthesia for 28 days. The bleomycin animal models were randomly divided into three groups (10 mice each) including the TLK117 group, PFD group, and TLK117 + PFD group. TLK117 group mice were administered oropharyngeally with $50 \mathrm{mg} / \mathrm{kg}$ TLK117 (once every 3 days) for another 28 days after treatment with bleomycin for 28 days. PFD group mice were fed with PFD by oral administration $(300 \mathrm{mg} / \mathrm{kg}$ daily for 28 days) after 28 days' treatment with bleomycin. The TLK117 + PFD group was simultaneously orally administrated with TLK117 and PFD as previously described. Afterward, all mice were killed. The lung tissue sections were collected and immediately frozen in liquid nitrogen for further studies. All experimental procedures were conducted in conformity with institutional guidelines for the care and use of laboratory animals, and protocols were approved by the Institutional Animal Care and Use Committee in Binzhou Medical University, Yantai, China (approval number: BZ2014-102R).

\section{RESULTS AND DISCUSSION}

Design Strategies for Probe Cy-GST. Small-molecule fluorescent probes exhibit superior ability to directly detect and image abnormal levels of enzymes in living systems. Despite remarkable entries acquired in the development of fluorescent probes for GSTs imaging, some challenges remain as obstacles toward applying these chemical tools from cell level to in vivo level and clinical applications. ${ }^{23,26}$ For a desirable GSTs fluorescent probe, high sensitivity and selectivity are the basic requirements. Additionally, high signal-to-noise contrast can improve the sensitivity of the new probe, such as a turn-on type enzymatic probe. For in vivo imaging of GSTs, NIR probes offer promising potential because of their low background fluorescence signal and deep penetration in tissue. The design of the probe Cy-GST begins with the selection of the response moiety. Previous research reveals that 3,4dinitrobenzanilide derivatives are specific substrates for recombinant human GSTs. ${ }^{26}$ We want to integrate 3,4dinitrobenzoic acid into a NIR fluorophore as the response moiety. The following procedure is to choose benzoheptamethine cyanine dye as the NIR fluorescence transmitter. As illustrated in Scheme 1, the response moiety will effectively

Scheme 1. Proposed Detection Mechanism of the Probe CyGST against GSTs

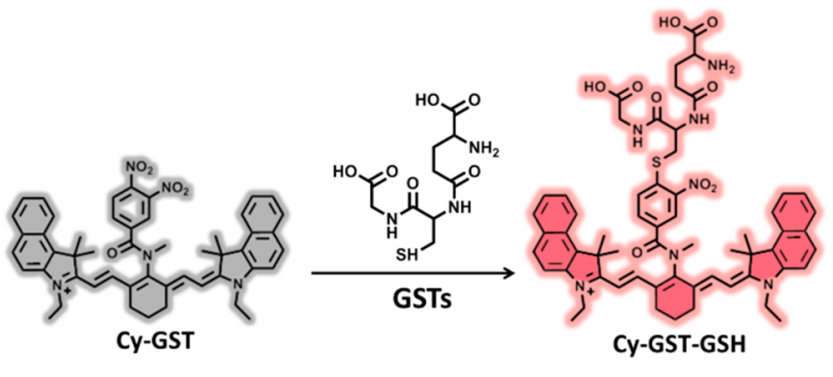

quench the fluorescence of the NIR platform. The optical regulation mechanism for this fluorescence quenching is attributed to the photoinduced electron-transfer (PET) process from the excited fluorophore to a strong electronwithdrawing group (donor-excited PET; dPET). ${ }^{33,34}$ Finally, we obtain the new probe Cy-GST for the detection of GSTs by specifically undergoing GST-catalyzed glutathionylation. After a two-step $S_{N} A r$ addition/elimination mechanism, the reaction between GSH and Cy-GST results in a sulfhydryl substitution derivative, Cy-GST-GSH, which hinders the process of dPET and induces the recovery of fluorescence. ${ }^{35}$ Using this probe, we will perform the detection and imaging of GSTs in living cells, in a mice model, and in clinical samples. The synthetic approaches of fluorescence probes Cy-GST is outlined in Scheme S2. All the compounds were characterized by ${ }^{1} \mathrm{H}$ NMR, ${ }^{13} \mathrm{C}$ NMR, and LC-MS (see Supporting Information).

Spectroscopic Properties. First, we investigated the effect of $\mathrm{pH}$ values for fluorescence intensity, which means that the probe would work well under physiological conditions (Figure S1). We investigated the absorption and the fluorescence spectral properties of Cy-GST toward GSTs under simulated physiological conditions (10 $\mathrm{mM} N$-(2-hydroxyethyl)piperazine- $N^{\prime}$-ethanesulfonic acid (HEPES) buffer $\mathrm{pH} 7.4$ ) in the presence of $0.1 \mathrm{mM}$ GSH. Both of the absorption and emission peaks located in the NIR spectral region (Figure 1a
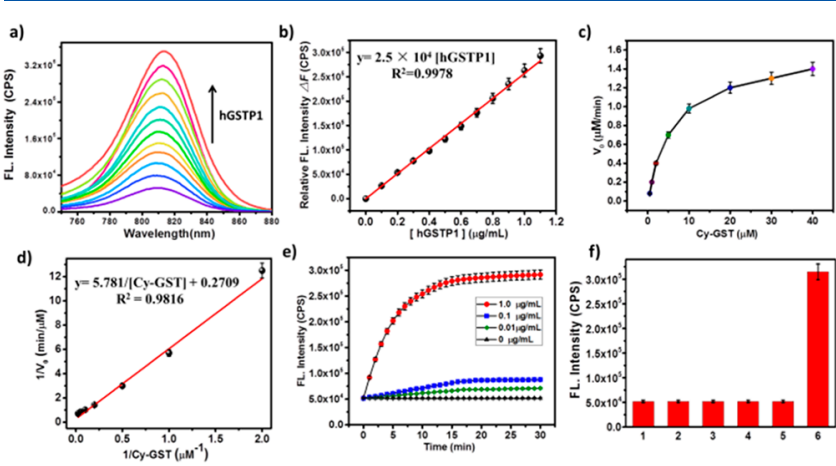

Figure 1. Spectral properties and enzymatic properties of Cy-GST in the presence of $0.1 \mathrm{mM} \mathrm{GSH}$ at $37^{\circ} \mathrm{C}$ and $10 \mathrm{mM}$ HEPES ( $\mathrm{pH} 7.4$ ) with $\lambda_{\mathrm{ex}} / \lambda_{\mathrm{em}}=730 / 810 \mathrm{~nm}$. (a) Fluorescence emission spectra changes of Cy-GST $(10 \mu \mathrm{M})$ with concentrations of hGSTP1 $(0,0.1$, $0.2,0.3,0.4,0.5,0.6,0.7,0.8,0.9,1.0$, and $1.1 \mu \mathrm{g} / \mathrm{mL}$ ). (b) Linear relationship between the relative fluorescence intensity and hGSTP1 $(0-1.1 \mu \mathrm{g} / \mathrm{mL})$. (c) Michaelis-Menten plot and (d) LineweaverBurke plot of the reaction between variable concentrations Cy-GST $(0.5-40 \mu \mathrm{M})$ and hGSTP1 $(1 \mu \mathrm{g} / \mathrm{mL})$. (e) Fluorescence intensity of Cy-GST $(10 \mu \mathrm{M})$ against the reaction time in the presence of concentrations of hGSTP1 $(0,0.01,0.1$, and $1.0 \mu \mathrm{g} / \mathrm{mL})$. (f) Fluorescence responses of Cy-GST $(10 \mu \mathrm{M})$ in the presence of 0.1 $\mathrm{mM}$ GSH to various analogous functional enzymes for $10 \mathrm{~min}$ : (1) horseradish peroxidase $(1.0 \mu \mathrm{g} / \mathrm{mL})$ [reduced nicotinamide adenine dinucleotide $(\mathrm{NADH})$ as coenzyme]; (2) nitroreductase $(1.0 \mu \mathrm{g} / \mathrm{mL})$ (NADH as coenzyme); (3) $\gamma$-glutamyl transpeptidase $(1.0 \mu \mathrm{g} / \mathrm{mL})$; (4) alkaline phosphatase $(1.0 \mu \mathrm{g} / \mathrm{mL})$; (5) $\beta$-galactosidase $(1.0 \mu \mathrm{g} /$ $\mathrm{mL})$; (6) hGSTP1 $(1.0 \mu \mathrm{g} / \mathrm{mL})$.

and Figure S2). There was little change in the absorption spectrum of Cy-GST after adding GSH (Figure S2). In contrast, the addition of a recombinant human GSTP1-1 (hGSTP1) induced an obvious increase in the absorption profile (Figure S2), which proved the necessity in using GSTs to catalyze the reaction between Cy-GST and GSH. We next investigated the fluorescence response of the probe toward different concentrations of hGSTP1. As shown in Figure 1b, the addition of hGSTP1 (from 0 to $1.1 \mu \mathrm{g} / \mathrm{mL}$ ) triggered the increases of NIR fluorescence emission. The fluorescence emission intensities at $810 \mathrm{~nm}$ were used to quantify the fluorescence response of Cy-GST to hGSTP1. The calibration curve was displayed in Figure $1 \mathrm{~b}$, which exhibited good linearity between relative fluorescence intensities and concen- 

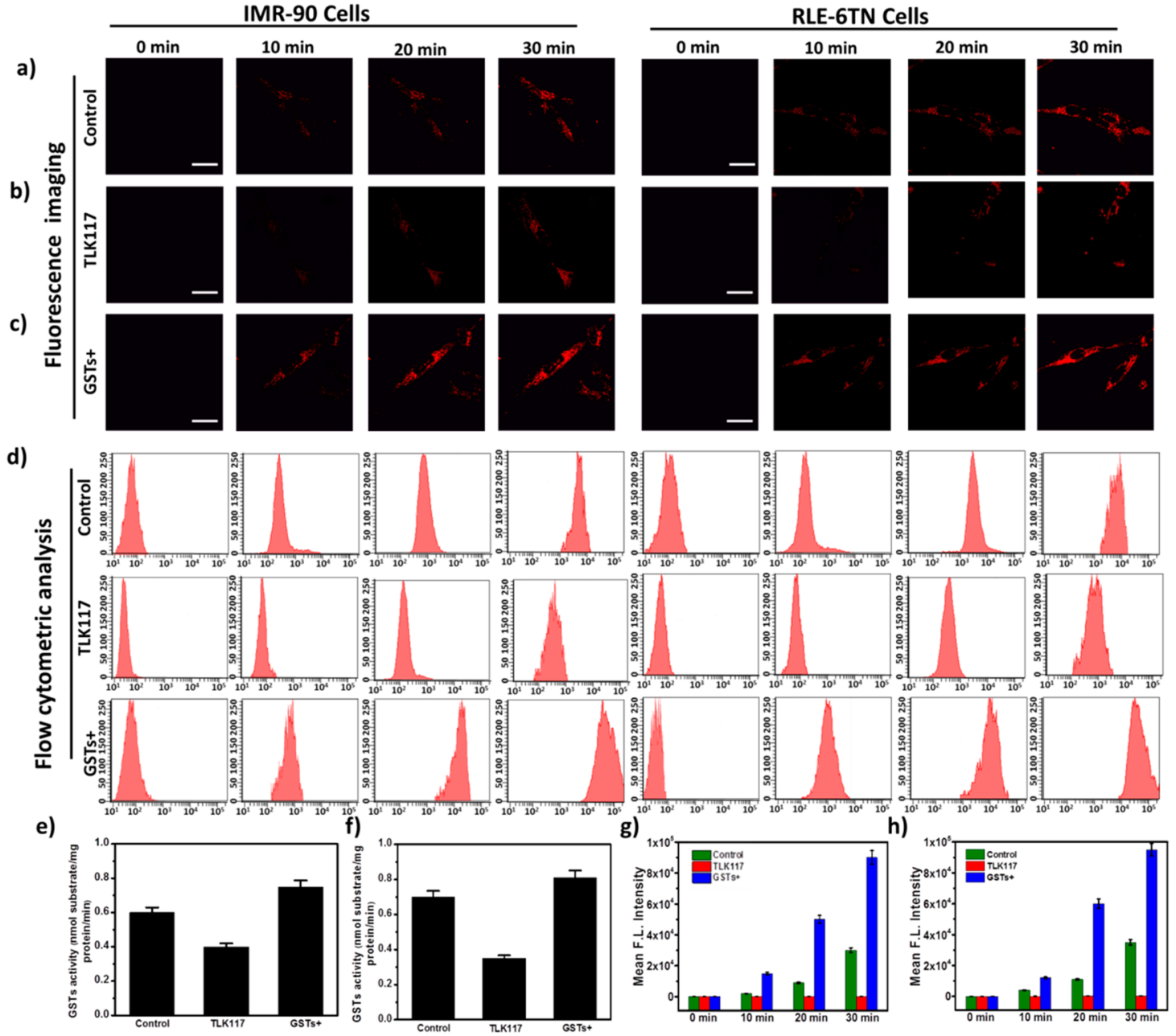

Figure 2. Confocal microscopy images and flow cytometry assay of IMR-90 and RLE-6TN cells for evaluating the fluctuation of GSTs in living cells. (a) Real-time GSTs quantification with Cy-GST $(5 \mu \mathrm{M})$ in IMR-90 and RLE-6TN cells at $37{ }^{\circ} \mathrm{C}$ at different time points: 0, 10, 20, and 30 min by confocal laser-scanning microscope with an objective lens $(60 \times)$ as control. (b) Before treatment as described in the control, IMR-90 cells and RLE-6TN cells were incubated with $50 \mu \mathrm{M}$ TLK117 for $24 \mathrm{~h}$ for imaging. (c) IMR-90 cells and RLE-6TN cells were treated as described in the control after IMR-90 cells and RLE-6TN cells of GSTs transfection. (d) Flow cytometry analysis of (a), (b), and (c). (e, f) Confirmation of decreased GSTs activity upon administration of TLK117 and increased GSTs activity upon GSTs transfection in IMR-90 cells and RLE-6TN cells. (g) Mean fluorescence intensity of IMR-90 cells. (h) Mean fluorescence intensity of RLE-6TN cells. (Red channel: $\lambda_{\text {ex }}=730 \mathrm{~nm}, \lambda_{\text {em }}=800-850$ $\mathrm{nm})$. Images are representative of $n=5$ independent experiments. Scale bars: $20 \mu \mathrm{m}$.

trations of hGSTP1 ranging from 1 to $1.1 \mu \mathrm{g} / \mathrm{mL}$. The regression equation was $\Delta\left(F-F_{0}\right)_{810 \mathrm{~nm}}=2.5 \times 10^{4}$ [hGSTP1] $(\mu \mathrm{g} / \mathrm{mL})$ with $R^{2}=0.9978$. Under the given experimental conditions, the limit of detection ( $3 \sigma /$ slope) toward hGSTP1 was determined to be $10 \mathrm{ng} / \mathrm{mL}$. The result suggested that our probe Cy-GST had high sensitivity for the response to hGSTP1, which indicates that Cy-GST has the potential for application in bioassays.

Reaction Kinetics of Cy-GST to GSTs. Because of the rapid metabolism and unstable properties of GSH and hGSTP1 in biological systems, the rapid response time played a crucial role in real-time detection. The kinetic study of the probe Cy-GST toward hGSTP1 was subsequently investigated. As illustrated in Figure 1c, different concentrations of Cy-GST $(0.5,1,2,5,10,20,30$, and $40 \mu \mathrm{M})$ were added into $1 \mu \mathrm{g} / \mathrm{mL}$ hGSTP1 solution. The reaction rate accelerated as the concentration of Cy-GST increased, suggesting that the activity of the enzyme was the rate-limiting factor. We selected the fluorescence intensities at $1 \mathrm{~min}$ as the basis for quantifying the initial velocity of the reaction. The fitted Lineweaver-
Burke equation $\left(1 / V_{0}(\mathrm{~min} / \mu \mathrm{M})=5.781 /[\mathrm{Cy}-\mathrm{GST}]+\right.$ 0.2709 , with $\left.R^{2}=0.9816\right)$ is shown in Figure $1 \mathrm{~d}$. The Michaelis constant $K_{\mathrm{M}}$ was calculated to be $21.34 \mu \mathrm{M}$. The turnover number $\left(k_{\text {cat }}\right)$ and the catalytic efficiency constant $\left(k_{\text {cat }} / K_{\mathrm{M}}\right)$ were determined to be $389 \mathrm{~s}^{-1}$ and $1.82 \times 10^{7} \mathrm{M}^{-1}$ $\mathrm{s}^{-1}$, respectively. These results proved that the probe should be a good substrate for hGSTP1. We also assessed the catalytic activity of hGSTP1 toward Cy-GST. Fluorescence kinetic curves of Cy-GST with different concentrations of hGSTP1 (0, $0.01,0.1$, and $1 \mu \mathrm{g} / \mathrm{mL})$ in the presence of GSH $(0.1 \mathrm{mM})$ were studied within $30 \mathrm{~min}$ (Figure 1e). It shows that the higher concentration of hGSTP1 gave a faster reaction and a larger fluorescence enhancement. When the hGSTP1 concentration was at $1 \mu \mathrm{g} / \mathrm{mL}$, the fluorescence signal could reach the plateau within $15 \mathrm{~min}$. The results illustrated that our probe had a fast response to hGSTP1. The fast reaction kinetics would be conducive to real-time detection in cells and in vivo.

Selectivity of Cy-GST toward GSTs. We next tested the fluorescent response of Cy-GST to other physiologically related species in HEPES buffer solution (10 mM, pH 7.4). 

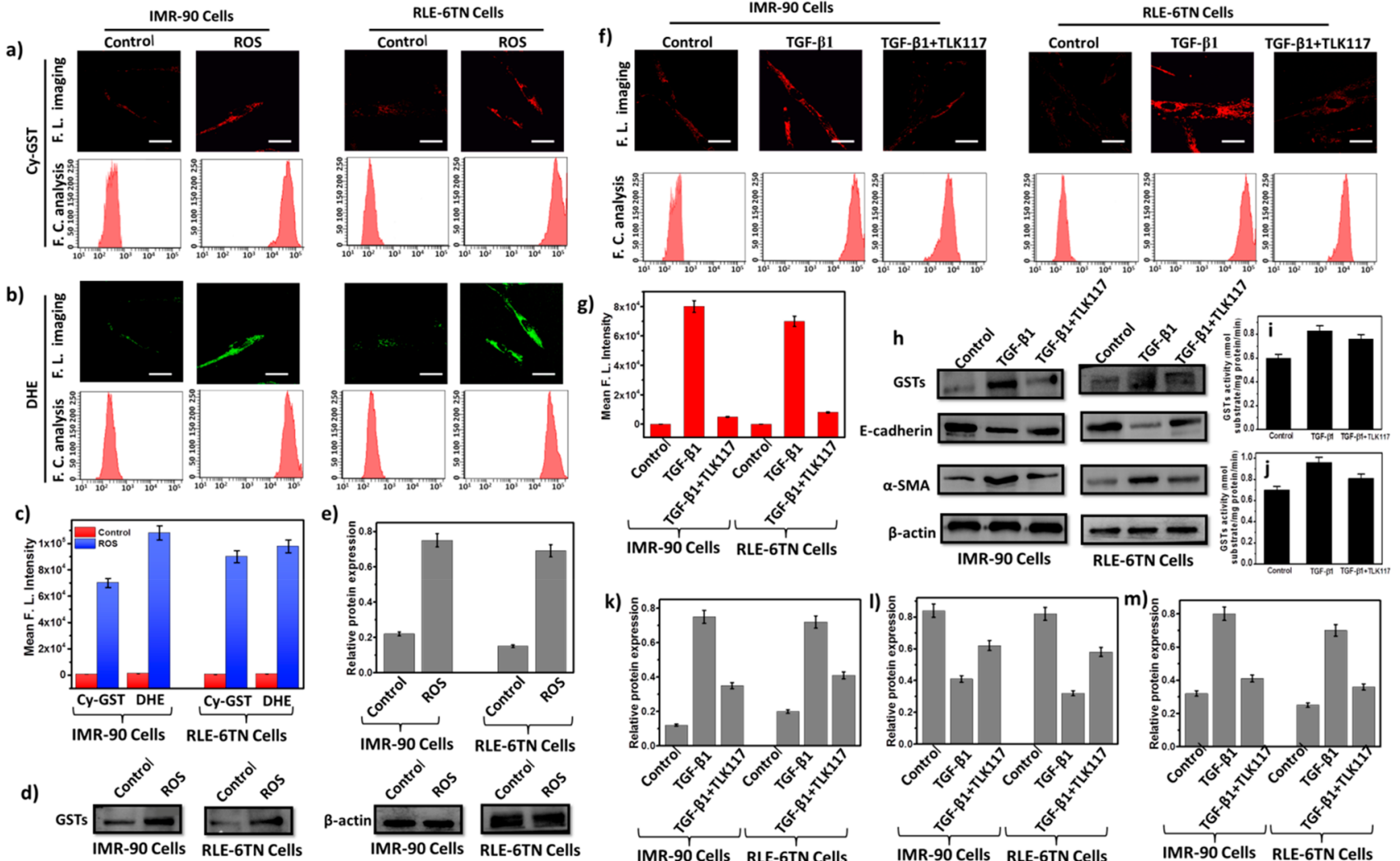

IMR-90 Cells RLE-6TN Cells
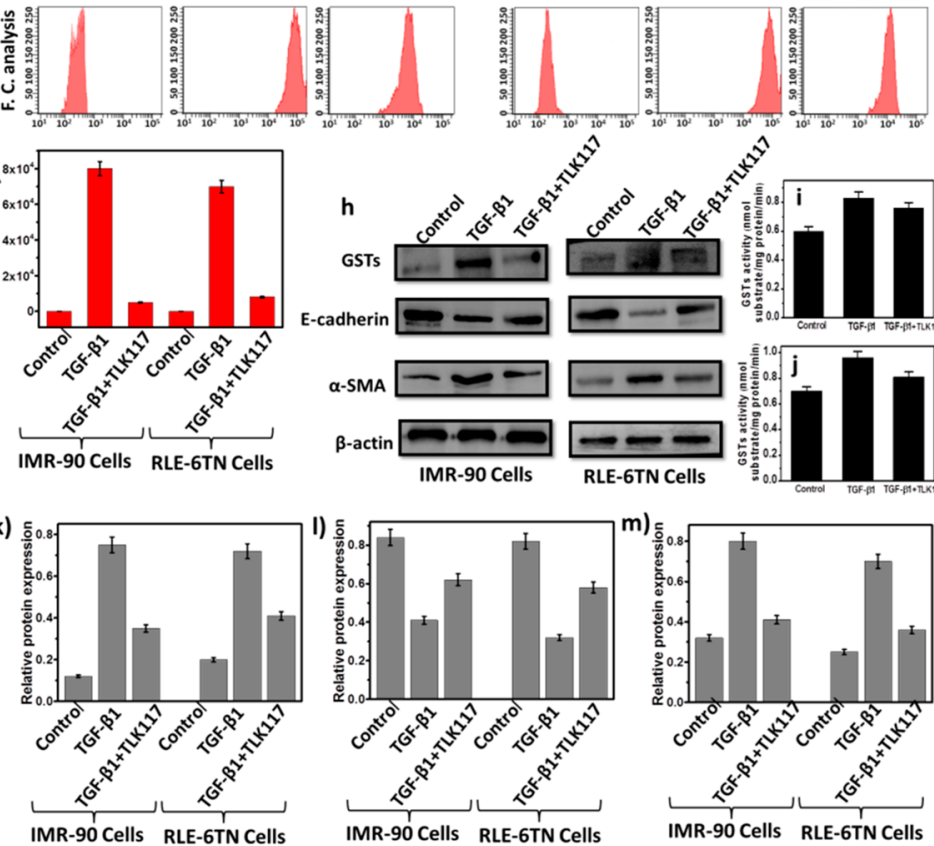

Figure 3. Fluctuation of GSTs and ROS in IMR-90 cells and RLE-6TN cells under oxidative stress conditions and pulmonary fibrosis cell models. (a) Confocal microscopy images and flow cytometry assay of GSTs with Cy-GST (5 $\mu \mathrm{M})$ in IMR-90 and RLE-6TN cells for 30 min as control. Before treatment as described in the control, the cells were incubated with $50 \mu \mathrm{M}$ paraquat for $8 \mathrm{~h}$. (b) Confocal microscopy images and flow cytometry assay of ROS with DHE $(10 \mu \mathrm{M})$ in IMR-90 and RLE-6TN cells for $30 \mathrm{~min}$ as control, then the cells were incubated with $50 \mu \mathrm{M}$ paraquat for $8 \mathrm{~h}$. (c) Mean fluorescence intensity of the images (a) and (b). (d) Western blot analysis GSTs protein changes of IMR-90 and RLE6TN cells. $\beta$-Actin was used as internal control. (e) Quantitative of GSTs protein expression in (d). (f) Real-time GSTs imaging with Cy-GST (5 $\mu \mathrm{M})$ in IMR-90 and RLE-6TN cells as control. Before treatment as described in the control, IMR-90 cells and RLE-6TN cells were incubated with $50 \mu \mathrm{M}$ TGF- $\beta 1$ for $72 \mathrm{~h}$ to establish the pulmonary fibrosis cell models. Pulmonary fibrosis cell models were incubated with $50 \mu \mathrm{M}$ TLK117 for 24 $\mathrm{h}$ and then processed according to the steps of the control group. (g) Mean fluorescence intensity of (f). (h) Western blot analysis GSTs protein, Ecadherin protein, and $\alpha$-SMA protein changes of IMR-90 and RLE-6TN cells in (f). Confirmation of GSTs activity in IMR-90 cells (i) and RLE6TN cells (j) of those shown in (f). $\beta$-actin was used as internal control. Quantitative GSTs protein (k), E-cadherin protein (l), and $\alpha$-SMA protein (m) expression in (h). Red channel: $\lambda_{\mathrm{ex}}=730 \mathrm{~nm}, \lambda_{\mathrm{em}}=800-850 \mathrm{~nm}$. Green channel: $\lambda_{\mathrm{ex}}=535 \mathrm{~nm}, \lambda_{\mathrm{em}}=590-610 \mathrm{~nm}$. Data are presented as mean \pm SD $(n=5)$. Scale bars: $20 \mu \mathrm{m}$.

As illustrated in Figure S3, the probe was incubated with various biospecies in the presence of hGSTP1, including $S$ nitrosoglutathione (GSNO), tocopherols, $\mathrm{Na}_{2} \mathrm{~S}_{4}$, L-cysteine (Lcys), NaHS, ascorbic acid, L-arginine (L-arg), tyrosine, homocystein, and glutathione (GSH). The results clearly indicated that only with both hGSTP1 and GSH could a remarkable increase of fluorescence emission be observed (Figure S3). In addition, the common metal ions and anions did not trigger any fluorescence enhancement (Figure S4). More importantly, various isozymes of hGSTP1 (including GSTA1, GSTM2, GSTO2, GSTT1, and GSTK1) exhibited the limited fluorescence response (Figure S5). The analogous functional enzymes (horseradish peroxidase, nitroreductase, $\gamma$ glutamyl transpeptidase, alkaline phosphatase, and $\beta$-galactosidase also could not cause any interference in our tests (Figure 1f). Our results indicated that Cy-GST possessed excellent selectivity toward hGSTP1 in the presence of various biologically relevant species under physiological conditions.

Imaging of GSTs in Living Cells. Because our probe CyGST exhibited good sensitivity and selectivity toward GSTs, we next investigated the potential utilization of Cy-GST for the detection of GSTs in different living cells. The IMR-90 cells (human embryonic lung fibroblast cell line) and RLE-6TN cells (rat type two alveolar epithelial cell line) were selected as the testing models. MTT assays were first performed to evaluate the cytotoxicity of Cy-GST in IMR-90 cells and RLE$6 \mathrm{TN}$ cells with probe concentrations from 0 to $100 \mu \mathrm{M}$. The results clearly demonstrated that the probe exhibited low cytotoxicity to living cells under experimental conditions (Figures S6 and S7). Cell imaging experiments were performed by utilizing laser scanning confocal microscopy. Both of the cell lines were incubated with Cy-GST for $30 \mathrm{~min}$ at $37^{\circ} \mathrm{C}$ before imaging. Then the flow cytometry was used to confirm the fluorescence changes. As illustrated in Figure 2, the two cell lines were divided into three groups, respectively. The second cell groups were pretreated with TLK117 (a commercial inhibitor of GSTs) for $24 \mathrm{~h}$ to consume the intracellular GSTs before imaging. The cell lines in the third group were transfected GSTs-RNA to overexpress GSTs. The control group in Figure 2a offered a gradual increase in fluorescence during the $30 \mathrm{~min}$ testing process. The fluorescence of Figure $2 \mathrm{~b}$ was much lower than that in Figure $2 \mathrm{a}$, indicating the lower GSTs activity in these cells. The higher fluorescence was observed Figure $2 c$ because of the high level of GSTs in cells. 

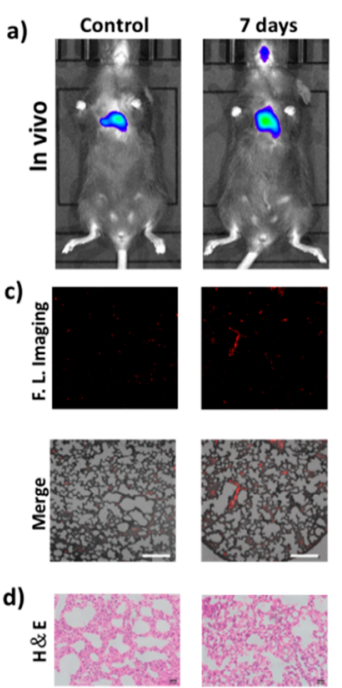

e)
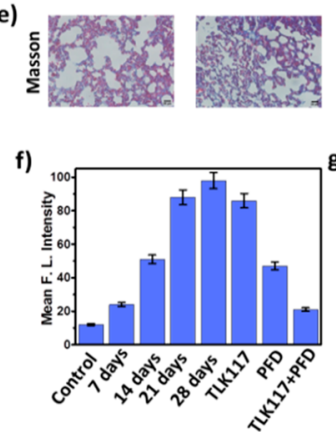
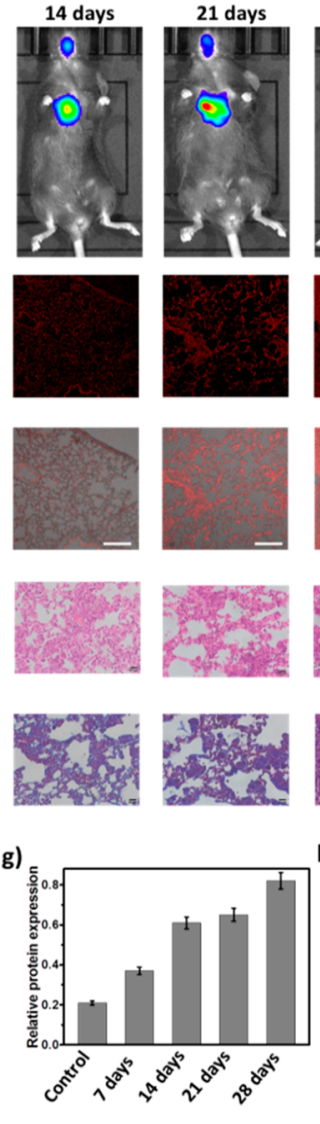
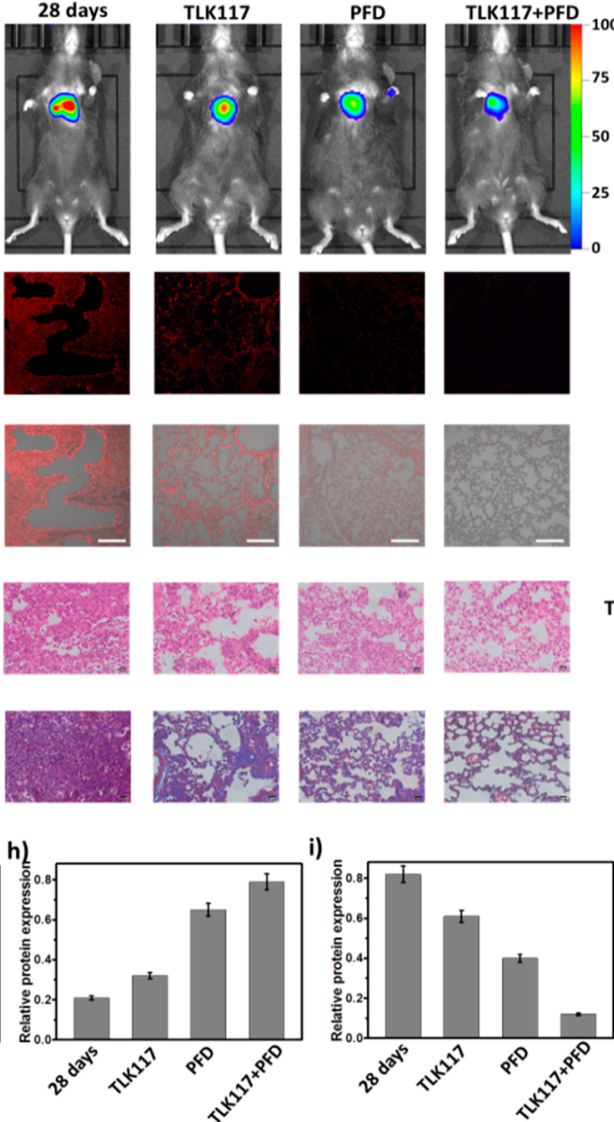

b) Heart Liver Spleen Lung Kidney

25
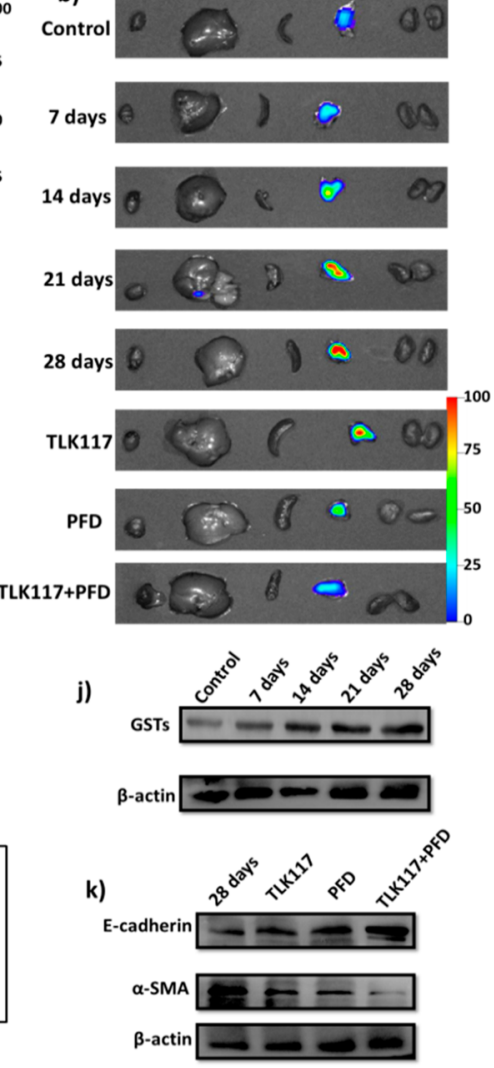

Figure 4. Imaging of GSTs level in pulmonary fibrosis mice models and the treatment effect of synergistic TLK117 and PFD. Fluorescence collection windows were the following: $800-850 \mathrm{~nm}, \lambda_{\mathrm{ex}}=730 \mathrm{~nm}$. (a) GSTs concentrations in different test groups according to different stimulus days by bleomycin: $0,7,14,21$, and 28 days. TLK117 group mice were administered oropharyngeally with $50 \mathrm{mg} / \mathrm{kg}$ TLK117 once every 3 days for 28 days after bleomycin treatment for 28 days. PFD group mice were orally administered $300 \mathrm{mg} / \mathrm{kg}$ PFD daily for 28 days after bleomycin treatment for 28 days. TLK117 + PFD group were simultaneously orally administered TLK117 and PFD as previously described. All pulmonary fibrosis mice models were incubated with Cy-GST $(100 \mu \mathrm{M}, 50 \mu \mathrm{L}$ in 1:99 DMSO/saline, v/v) for 30 min with intratracheal administration before fluorescence imaging in vivo. (b) Fluorescence imaging of isolated organs (heart, liver, spleen, lungs, and kidneys) imaging. (c) Fluorescence imaging and merged imaging of fluorescence and bright-field imaging (Figure S11) of lung slices of different test groups by treatment with Cy-GST. Scale bar: $60 \mu \mathrm{m}$. (d) H\&E pathology of different test groups. (e) Masson pathology of different test groups. (f) Mean fluorescence intensity of the images (a). (g) Quantitation of GSTs protein expression in (j). Quantitation of E-cadherin protein (h) and $\alpha$-SMA protein (i) expression in (k). (j) Western blot analysis GSTs protein changes of lung tissue in different stimulus days by bleomycin; $\beta$-actin was used as internal control. (k) Western blot analysis E-cadherin protein and $\alpha$-SMA protein changes of lung tissue in different test groups; $\beta$-actin was used as internal control. Fluorescence imaging channel: $\lambda_{\mathrm{ex}}=730 \mathrm{~nm}, \lambda_{\mathrm{em}}=800-850 \mathrm{~nm}$. Data are presented as mean $\pm \mathrm{SD}(n=5)$.

The bright-field images of parts (a)-(c) in Figure 2 are shown in Figure S8. Flow cytometry analysis was performed to validate the above results (Figure $2 \mathrm{~d}$ ). These results were consistent with the fluorescence images results. Additionally, we examined the enzyme activity of GSTs in the three different groups of cells (Figure 2e,f). It was consistent with those received from laser scanning confocal microscopy and flow cytometry analysis. The mean fluorescence intensity of IMR-90 cells and RLE-6TN cells are shown in Figure 2g,h. These results illustrated that the probe Cy-GST could be applied as a facilitative tool to directly image GSTs in living cells.

Level Changes of GSTs in Pulmonary Fibrosis Cell Models. The patient with IPF suffers high levels of oxidant stress, which induces the increase of GSTs levels. ${ }^{36,37}$ Therefore, before investigating the relationship between pulmonary fibrosis and GSTs, we first verified the correlation between oxidative stress and GSTs. The probe Cy-GST was further employed to detect the variation of GSTs concentrations under oxidative stress conditions. As displayed in parts (a) and (b) of Figure 3, IMR-90 cells and RLE-6TN cells were incubated with $50 \mu \mathrm{M}$ paraquat for $8 \mathrm{~h}$ to provide the overproduction of $\mathrm{O}_{2}{ }^{--}$, which would result in cellular oxidative stress. Before imaging, the two cell lines were incubated with Cy-GST for $30 \mathrm{~min}$ at $37{ }^{\circ} \mathrm{C}$. We also detected the oxidative stress state utilizing a commercial fluorescent probe dihydroethidium (DHE). The strong fluorescence in the green channel indicated that the stimulation with paraquat could lead to a severe oxidative stress state. As expected, the cells by treatment with paraquat also emitted strong fluorescence in the red channel, indicating the higher level of GSTs (Figure 3a). The mean fluorescence intensity of cell imaging is shown in Figure 3c. The results revealed a fact that the intracellular GSTs level would increase under the oxidative stress condition in living cells. The bright-field images in parts (a) and (b) of Figure 3 are shown in Figure S9. The data of laser scanning confocal microscopy were further confirmed by flow cytometry (Figure $3 \mathrm{a}$ and $2 \mathrm{~b}$ ). The levels of GSTs were checked via Western blot (Figure 3d,e). 
Having confirmed that oxidative stress could induce the increase of intracellular GST level, we attempted to explore the relationship between GSTs levels and pulmonary fibrosis. We established the pulmonary fibrosis cell models using IMR-90 cells and RLE-6TN cells by incubating with $50 \mu \mathrm{M}$ TGF- $\beta 1$ for $72 \mathrm{~h}$. The controls in Figure 3a were incubated with Cy-GST for $30 \mathrm{~min}$ at $37{ }^{\circ} \mathrm{C}$. The basic fluorescence showed the endogenous level of GSTs in IMR-90 cells and RLE-6TN cells. And the pulmonary fibrosis cell models offered higher fluorescence, which demonstrated that there were higher GSTs concentrations in these cells. If the pulmonary fibrosis cell models were pretreated with the inhibitor TLK117, a lower fluorescence due to the lower activity of GSTs would be obtained. The results were consistent with flow cytometry analysis (Figure 3f). And the mean fluorescence intensity of cell imaging was shown in Figure 3g. The bright-field images of Figure $3 \mathrm{f}$ are shown in Figure S10. Western blot displayed the changes in GSTs levels in cell models (Figure 3h,k). In addition, as shown in Figure 3i,j, we also evaluated the GSTs activity of every group in Figure 3f, which reflected the fluctuation of GSTs activity. E-cadherin protein and $\alpha$-smooth muscle actin ( $\alpha$-SMA) protein were commonly used to indicate the severity of pulmonary fibrosis. The level of Ecadherin protein decreased and the level of $\alpha$-SMA protein increased in the pulmonary fibrosis cell models, which illustrated that the cells incubated with TGF- $\beta 1$ were more severe than the cells in controls, while the treatment of TLK117 could result in the E-cadherin protein increasing and $\alpha$-SMA protein decreasing, which illustrated that the level of pulmonary fibrosis in the therapy group was more mild (Figure $3 \mathrm{~h}, \mathrm{l}, \mathrm{m})$. These results confirmed that the level of GSTs in the pulmonary fibrosis cell models is higher than those in the normal cells, and the level of intracellular GSTs had a close relationship with the degrees of pulmonary fibrosis. The inhibition of GSTs was beneficial to the relieving of pulmonary fibrosis.

Imaging of GSTs in Pulmonary Fibrosis Mice Models. We further examined the efficiency in using Cy-GST in mice models with pulmonary fibrosis. The $\mathrm{C} 57 \mathrm{Bl} / 6$ mice were chosen as the testing animal models and used in experiments after using bleomycin to induce pulmonary fibrosis. To acquire the level changes of GSTs during the formation process of pulmonary fibrosis, the mice models were divided into five groups according to different stimulus days: $0,7,14,21$, and 28 days. We measured the GSTs concentrations in different testing groups using an in vivo imaging system. Cy-GST (10 $\mu \mathrm{M}, 200 \mu \mathrm{L}$, in DMSO:saline $=1: 99, \mathrm{v} / \mathrm{v}$ ) was administered intratracheally $1 \mathrm{~h}$ before fluorescence images were taken in vivo (fluorescence collection window was $800-850 \mathrm{~nm}$ with an excitation wavelength at $730 \mathrm{~nm}$ ). Along with the stimulating time, the fluorescence intensities of the mice models became stronger, which illustrated that the level of GSTs increased with the severity of pulmonary fibrosis (Figure $4 a)$. Ex vivo fluorescence images of the isolated assay displayed that the obvious fluorescence signal appeared in the lungs, instead of other organs, including heart, liver, spleen, and kidneys (Figure 4b). The average fluorescence intensities are shown in Figure 4f. To further assess the level changes of GSTs, we carried out fluorescence imaging of the lung slices (Figure 4c) and Western blot analysis (Figure 4j). Quantitative GSTs protein expression of lung slices is shown in Figure $4 \mathrm{~g}$. The results were very consistent with those from in vivo and ex vivo imaging assays. The fluorescence signals in the lungs became stronger with the severity of pulmonary fibrosis. H\&E and Masson staining were performed to confirm the model of pulmonary fibrosis (Figure $4 \mathrm{~d}, \mathrm{e}$ ). These results demonstrated the potential relationship between the levels of GSTs and the degrees of pulmonary fibrosis. GSTs might play a vital role in the occurrence and development process of idiopathic pulmonary fibrosis.

Because we had illustrated the potential relationship between the GSTs levels and the degrees of pulmonary fibrosis, we next examined whether the inhibition of GSTs activity had effects on the treatment of pulmonary fibrosis or not. GSTP was expressed primarily in the lungs, brain, and gastrointestinal tract, which was a mediator of S-glutathionylation in lung airway epithelial cells. The present study implied that both genetic ablation of GSTP and pharmacological inhibition of GSTP with a clinically relevant inhibitor TLK117 could decrease the collagen content, $\alpha$-SMA immunoreactivity, FAS-SSG, and total PSSG in pulmonary fibrosis mice models. That is, the interaction of FAS/GSTP and GSTP immunoreactivity increased in lungs of IPF patients. The expression and activity of GSTP will lead to the progression of lung fibrogenesis. ${ }^{38}$ The pharmacological inhibition of GSTP might represent a new therapeutic strategy for the treatment of pulmonary fibrosis disease. The pulmonary fibrosis mice models were established via inducement of bleomycin for 28 days. Three groups of pulmonary fibrosis mice were selected for performing the treatment trials: the mice in the first group were oropharyngeally administered with $50 \mathrm{mg} / \mathrm{kg}$ TLK117 once every 3 days for 28 days. PFD had been employed as the clinical drug for the treatment of pulmonary fibrosis. The second group was orally administered $300 \mathrm{mg} / \mathrm{kg}$ PFD daily for 28 days. The third group was simultaneously orally administered with TLK117 and PFD as described in the above two groups. As shown in Figure 4a, the fluorescent signal in the third therapy group (TLK117 + PFD) was much weaker than that individually treated with TLK117 or PFD. The results suggested that the levels of GSTs decreased accompanied by the synergistic treatment of TLK117 and PFD. The fluorescence images of isolated organs, lung slices, and Western blot analysis all verified the change in GSTs (Figure 4b,c,j). $H \& E$ and Masson sections of mice lung tissue are shown in Figure 4 d,e. The results of the severity of pulmonary fibrosis could be presented in the following order: model group > TLK117 group $>$ PFD group $>$ TLK117 + PFD group. The changes in E-cadherin protein and $\alpha$-SMA protein were also consistent with the above results (Figure $4 \mathrm{~h}, \mathrm{i}, \mathrm{k}$ ). These results revealed that the inhibitor (TLK117) of GSTs had positive effects on the treatment of pulmonary fibrosis. Furthermore, the synergistic treatment of TLK117 and PFD exhibited better therapeutic effects than treatment with only TLK117 or PFD. Therefore, the inhibition of GSTs might be considered as a new synergistic therapeutic strategy for pulmonary fibrosis therapy.

Imaging of GSTs in the Sample of IPF Patient. Because we had illustrated that the levels of GSTs increased along with the severity of pulmonary fibrosis in cells and mice models, taking advantage of our probe Cy-GST, we next investigated whether the level of GSTs increased in IPF patients. Lung tissue samples were obtained by the fiberoptic bronch biopsy and were snap-frozen in OCT (optimal cutting temperature compound). Then the samples were sectioned with $4 \mu \mathrm{m}$ thickness using a microtome. After these slices were transferred into a storage chamber, the slices rested at room temperature 
for at least $1 \mathrm{~h}$; prior to staining for fluorescence imaging analysis, the slices were treated with $50 \mu \mathrm{M}$ Cy-GST for 30 min and then washed with PBS buffer solution three times before imaging by laser scanning confocal microscope. The fluorescence images of human lung tissue sections were collected to prove the level changes of GSTs. As illustrated in Figure 5, the sample of the non-IPF patient group emitted

\begin{tabular}{|c|c|c|c|c|c|}
\hline \multicolumn{3}{|c|}{ Healthy Control } & \multicolumn{3}{|c|}{ Pulmonary Fibrosis Patient } \\
\hline F. L. Imaging & Bright Field & Merge & F. L. Imaging & Bright Field & Merge \\
\hline
\end{tabular}

Figure 5. Fluorescence imaging of GSTs in the lung tissues of healthy control and IPF patient groups $\left(\lambda_{\mathrm{ex}}=730 \mathrm{~nm}\right.$, fluorescence collection window: $800-850 \mathrm{~nm})$. Shown are the data from two independent experiments ( $n=6$ in each group). Scale bars: $60 \mu \mathrm{m}$.

only low fluorescence. In contrast, high fluorescent intensity can be observed in the sample of IPF patient, indicating higher GSTs concentration in IPF patient group compared to that of the healthy control. These results clearly indicated that the levels of GSTs increased in the lung tissue of the IPF patient investigated in our experiment.

\section{CONCLUSION}

We have developed a NIR fluorescent probe Cy-GST for the evaluation of GSTs level changes in living cells and in mice models during the development of pulmonary fibrosis. With the help of Cy-GST, we confirm that the intracellular GSTs play important roles in the severity of pulmonary fibrosis. Pulmonary fibrosis also results in the intracellular oxidative stress state, which also induced the increase of GSTs levels. Our results demonstrate that the level of GSTs in the pulmonary fibrosis cell models is higher than that in normal cells. To further demonstrate the potential relationship between GSTs and pulmonary fibrosis, we also confirm the level changes of GSTs in pulmonary fibrosis mice models and in IPF patients. And we suggest that the synergistic administration of GSTs inhibitor TLK117 and PFD has better therapeutic effect than administration with TLK117 or PFD alone. Our probe is a benefit of the development of new chemical tools for accurate diagnosis of IPF, and the administration of GSTs inhibitor may be a new therapeutic strategy of IPF therapy.

\section{ASSOCIATED CONTENT}

\section{S Supporting Information}

The Supporting Information is available free of charge on the ACS Publications website at DOI: 10.1021/acs.analchem.9b00713.

Experimental section; synthetic routes for compound 1; $\mathrm{pH}$ effects on the probe Cy-GST; absorption spectra of Cy-GST; selectivity of Cy-GST to various biospecies; MTT assay for Cy-GST; bright-field cell images of those shown in Figure 2 (in manuscript); bright-field cell images of those shown in Figure 3a,b; bright-field cell images of those shown in Figure 3f; bright-field images of those shown in Figure 4c; characterization $\left({ }^{1} \mathrm{H}\right.$ NMR, ${ }^{13} \mathrm{C}$ NMR, and LC-MS) of synthesized compounds (1, 2, and Cy-GST); LC-MS characterization of the product Cy-GST-GSH; references (PDF)

\section{AUTHOR INFORMATION}

\section{Corresponding Authors}

*E-mail: 1xchen@yic.ac.cn (L.C.).

*E-mail: fbyu@yic.ac.cn (F.Y.).

*E-mail: lucky_lcj@sina.com (C.L.).

ORCID $\odot$

Lingxin Chen: 0000-0002-3764-3515

Fabiao Yu: 0000-0003-0073-6299

\section{Author Contributions}

${ }^{\#}$ N.H. and S.B. contributed equally to this work.

Notes

The authors declare no competing financial interest.

\section{ACKNOWLEDGMENTS}

We thank the National Nature Science Foundation of China (No. 21775162, 21864011, 81670064, and 81870001), Talent Program of Hainan Medical University (Grants XRC180006 and XRC180007), Hundred-Talent Program (Hainan 2018), and Medical Science and Technology Development Project of Shandong Province (Grant 2017WS800).

\section{REFERENCES}

(1) Bonella, F.; Stowasser, S.; Wollin, L. Drug Des., Dev. Ther. 2015, 9, 6407-6419.

(2) King, T. J.; Bradford, W. Z.; Castro-Bernardini, S.; Fagan, E. A.; Glaspole, I.; Glassberg, M. K.; Gorina, E.; Hopkins, P. M.; Kardatzke, D.; Lancaster, L.; Lederer, D. J.; Nathan, S. D.; Pereira, C. A.; Sahn, S. A.; Sussman, R.; Swigris, J. J.; Noble, P. W. N. Engl. J. Med. 2014, 370, 2083-2092.

(3) Richeldi, L.; du Bois, R. M.; Raghu, G.; Azuma, A.; Brown, K. K.; Costabel, U.; Cottin, V.; Flaherty, K. R.; Hansell, D. M.; Inoue, Y.; Kim, D. S.; Kolb, M.; Nicholson, A. G.; Noble, P. W.; Selman, M.; Taniguchi, H.; Brun, M.; Le Maulf, F.; Girard, M.; Stowasser, S.; Schlenker-Herceg, R.; Disse, B.; Collard, H. R. N. Engl. J. Med. 2014, 370, 2071-2082.

(4) Martinez, F. J.; Safrin, S.; Weycker, D.; Starko, K. M.; Bradford, W. Z.; King, T. J.; Flaherty, K. R.; Schwartz, D. A.; Noble, P. W.; Raghu, G.; Brown, K. K. Ann. Intern. Med. 2005, 142, 963-967.

(5) Cantin, A. M.; North, S. L.; Fells, G. A.; Hubbard, R. C.; Crystal, R. G. J. Clin. Invest. 1987, 79, 1665-1673.

(6) Meyer, A.; Buhl, R.; Kampf, S.; Magnussen, H. Am. J. Respir. Crit. Care Med. 1995, 152, 1055-1060.

(7) Strange, R. C.; Jones, P. W.; Fryer, A. A. Toxicol. Lett. 2000, 112, $357-363$

(8) Janssen-Heininger, Y. M.; Aesif, S. W.; van der Velden, J.; Guala, A. S.; Reiss, J. N.; Roberson, E. C.; Budd, R. C.; Reynaert, N. L.; Anathy, V. Ann. N. Y. Acad. Sci. 2010, 1203, 23-28.

(9) Misquitta, S. A.; Colman, R. F. Biochemistry 2005, 44, 86088619.

(10) Ralat, L. A.; Colman, R. F. J. Biol. Chem. 2004, 279, 5020450213.

(11) Vargo, M. A.; Nguyen, L.; Colman, R. F. Biochemistry 2004, 43, 3327-3335.

(12) Ren, S.; Zhou, F.; Xu, C.; Li, B. Gold Bull. 2015, 48, 147-152.

(13) Zhou, W.; Shultz, J. W.; Murphy, N.; Hawkins, E. M.; Bernad, L.; Good, T.; Moothart, L.; Frackman, S.; Klaubert, D. H.; Bulleit, R. F.; Wood, K. V. Chem. Commun. (Cambridge, U. K.) 2006, 44, 46204622.

(14) Marx, V. Nat. Methods 2014, 11, 717-720.

(15) Yang, Y.; Zhao, Q.; Feng, W.; Li, F. Chem. Rev. 2013, 113, 192-270.

(16) Li, X.; Gao, X.; Shi, W.; Ma, H. Chem. Rev. 2014, 114, 590659.

(17) Chen, X.; Zhou, Y.; Peng, X.; Yoon, J. Chem. Soc. Rev. 2010, 39, 2120-2135. 
(18) Mei, J.; Leung, N. L.; Kwok, R. T.; Lam, J. W.; Tang, B. Z.

Chem. Rev. 2015, 115, 11718-11940.

(19) Wu, D.; Sedgwick, A. C.; Gunnlaugsson, T.; Akkaya, E. U.; Yoon, J.; James, T. D. Chem. Soc. Rev. 2017, 46, 7105-7123.

(20) Fan, J.; Hu, M.; Zhan, P.; Peng, X. Chem. Soc. Rev. 2013, 42, $29-43$.

(21) Hou, J. T.; Ren, W. X.; Li, K.; Seo, J.; Sharma, A.; Yu, X. Q.; Kim, J. S. Chem. Soc. Rev. 2017, 46, 2076-2090.

(22) Verwilst, P.; Kim, H. S.; Kim, S.; Kang, C.; Kim, J. S. Chem. Soc. Rev. 2018, 47, 2249-2265.

(23) Liu, H. W.; Chen, L.; Xu, C.; Li, Z.; Zhang, H.; Zhang, X. B.; Tan, W. Chem. Soc. Rev. 2018, 47, 7140-7180.

(24) Zhou, J.; Ma, H. Chem. Sci. 2016, 7, 6309-6315.

(25) Gao, M.; Yu, F.; Lv, C.; Choo, J.; Chen, L. Chem. Soc. Rev. 2017, 46, 2237-2271.

(26) Fujikawa, Y.; Urano, Y.; Komatsu, T.; Hanaoka, K.; Kojima, H.; Terai, T.; Inoue, H.; Nagano, T. J. Am. Chem. Soc. 2008, 130, 1453314543.

(27) Zhang, J.; Shibata, A.; Ito, M.; Shuto, S.; Ito, Y.; Mannervik, B.; Abe, H.; Morgenstern, R. J. Am. Chem. Soc. 2011, 133, 14109-14119.

(28) Arttamangkul, S.; Bhalgat, M. K.; Haugland, R. P.; Diwu, Z.;

Liu, J.; Klaubert, D. H.; Haugland, R. P. Anal. Biochem. 1999, 269, 410-417.

(29) Svensson, R.; Greno, C.; Johansson, A. S.; Mannervik, B.; Morgenstern, R. Anal. Biochem. 2002, 311, 171-178.

(30) Zhang, J.; Jin, Z.; Hu, X. X.; Meng, H. M.; Li, J.; Zhang, X. B.; Liu, H. W.; Deng, T.; Yao, S.; Feng, L. Anal. Chem. 2017, 89, 80978103.

(31) Kobayashi, H.; Ogawa, M.; Alford, R.; Choyke, P. L.; Urano, Y. Chem. Rev. 2010, 110, 2620-2640.

(32) Yuan, L.; Lin, W.; Zheng, K.; He, L.; Huang, W. Chem. Soc. Rev. 2013, 42, 622-661.

(33) Ueno, T.; Urano, Y.; Kojima, H.; Nagano, T. J. Am. Chem. Soc. 2006, 128, 10640-10641.

(34) Yu, F.; Li, P.; Song, P.; Wang, B.; Zhao, J.; Han, K. Chem. Commun. (Cambridge, U. K.) 2012, 48, 4980-4982.

(35) Kiyose, K.; Aizawa, S.; Sasaki, E.; Kojima, H.; Hanaoka, K.; Terai, T.; Urano, Y.; Nagano, T. Chem. - Eur. J. 2009, 15, 9191-9200. (36) Kinnula, V. L.; Fattman, C. L.; Tan, R. J.; Oury, T. D. Am. J. Respir. Crit. Care Med. 2005, 172, 417-422.

(37) Xie, C.; Lovell, M. A.; Xiong, S.; Kindy, M. S.; Guo, J.; Xie, J.; Amaranth, V.; Montine, T. J.; Markesbery, W. R. Free Radical Biol. Med. 2001, 31, 73-81.

(38) McMillan, D. H.; van der Velden, J. L.; Lahue, K. G.; Qian, X.; Schneider, R. W.; Iberg, M. S.; Nolin, J. D.; Abdalla, S.; Casey, D. T.; Tew, K. D.; Townsend, D. M.; Henderson, C. J.; Wolf, C. R.; Butnor, K. J.; Taatjes, D. J.; Budd, R. C.; Irvin, C. G.; van der Vliet, A.; Flemer, S.; Anathy, V.; Janssen-Heininger, Y. M. JCI Insight. 2016, 1, 85717. 